\title{
Composição da matéria orgânica em sedimentos do Reservatório do Funil, Resende, Rio de Janeiro, Brasil
}

\author{
Pauliana Firmina \\ Cordeiro Fraga de Almeida ${ }^{1}$ \\ Laís Rodrigues Barbosa ${ }^{1}$ \\ Tatiana Santos da Cunha ${ }^{2}$ \\ Marcelo Corrêa Bernardes ${ }^{1 *}$ \\ Luciana de Oliveira Vidal ${ }^{3}$ \\ Fabio Roland ${ }^{3}$ \\ ${ }^{1}$ Programa de Geoquímica, \\ Universidade Federal Fluminense (UFF) - \\ Niterói (RJ), Brasil. \\ ${ }^{2}$ Centro Universitário Estadual da Zona \\ Oeste (UEZO) - Rio de Janeiro (RJ), Brasil. \\ ${ }^{3}$ Programa de Ecologia, Universidade \\ Federal de Juiz de Fora (UFJF) - \\ Juiz de Fora (MG), Brasil. \\ * Autor correspondente: \\ uff.bernardes@gmail.com
}

\begin{abstract}
Resumo
Todos os corpos d'água continentais, naturais ou antrópicos, emitem gases do efeito estufa. Em reservatórios construídos para geração de energia elétrica, a intensidade de emissão está diretamente relacionada à idade a ao tipo de vegetação inundada. Este trabalho teve como objetivo obter uma caracterização da matéria orgânica (MO) em sedimentos do Reservatório do Funil (RJ), construído há cinco décadas no leito do Rio Paraíba do Sul para geração de energia elétrica. As análises das composições elementares $(\mathrm{C} / \mathrm{N})$, isotópicas $\left(\delta^{13} \mathrm{C}\right.$ e $\left.\delta^{15} \mathrm{~N}\right)$ e moleculares (esteróis e $n$-alcanos) demonstraram o predomínio da entrada de fonte alóctone pelo escoamento superficial de solos ricos em restos de plantas terrestres. Somados a essa entrada foram detectados em toda a extensão do Reservatório $n$-alcanos característicos de floresta inundada devido à predominância dos compostos $\mathrm{C}_{29}, \mathrm{C}_{31}$ e $\mathrm{C}_{33}$, com a presença de mistura complexa não resolvida (MCNR). No entanto, por meio do esterol fecal coprostanol foi observado que o Reservatório do Funil recebe influência de efluentes domésticos, tornando-se altamente contaminado no ponto central. A diminuição da razão C: $\mathrm{N}$ e da proporção dos lipídios terrígenos sobre os aquáticos na porção central e a jusante sugere intensificação de atividades fitoplanctônicas e bacterianas. Apesar da condição eutrófica do reservatório, nota-se que a sedimentação e os processos autóctones atuam depurando compostos orgânicos e exportando material refratário para o Rio Paraíba do Sul. Palavras-chave: isótopos estáveis, $n$-alcanos, esteróis, coprostanol, eutrofização.
\end{abstract}

\section{Abstract}

Natural lakes and man-made reservoirs emit greenhouse gases. In reservoirs constructed for electric power generation, the greenhouse gases emission is directly related to the age and to the type of flooded vegetation. This study aimed to obtain a characterization of organic matter in sediments from Funil Reservoir (RJ, Brazil), built five decades ago in the main channel of the Paraiba do Sul River to generate electricity. The analysis of the elemental $(\mathrm{C} / \mathrm{N})$, isotopic $\left(\delta^{13} \mathrm{C}\right.$ and $\left.\delta^{15} \mathrm{~N}\right)$ and molecular (sterols and n-alkanes) compositions demonstrate the predominance entrance of allochthonous source through runoff with soils rich in terrestrial plant debris. Along the entire length of the reservoir n-alkanes results showed signs of flooded forest due to the predominance of the compounds $C_{29}$, $\mathrm{C}_{31}$ and $\mathrm{C}_{33}$, and the presence of unresolved complex mixture (UCM). However, through the fecal sterol coprostanol, it was observed that the Funil Reservoir is influenced by domestic sewage becoming contaminated at the the center station. The decrease in C: $N$ ratio and the lower proportion of terrigenous lipids in the central portion and downstream, 
suggests intensification of phytoplankton and bacterial activities. Despite the eutrophic condition of the reservoir, we note that sedimentation and autochthonous processes act debugging organic compounds, and exporting refractory material for the Paraiba do Sul River.

Keywords: stable isotopes, n-alkanes, sterols, coprostanol, eutrophication.

\section{INTRODUÇÃO}

Com o relativo desenvolvimento econômico, urbano e industrial do Brasil definido para os próximos anos, cresce cada vez mais a necessidade de produção energética. A energia elétrica produzida pelas grandes hidrelétricas brasileiras tem um papel importante no desenvolvimento do país, além de ser uma alternativa renovável e de baixo custo. No entanto, hidrelétricas, em sua maioria, constroem reservatórios artificiais de água doce que inundam grandes áreas de biomassa vegetal. Esta, principalmente nos primeiros anos, é decomposta produzindo material refratário e gases do efeito estufa (GEEs) que são emitidos para a atmosfera.

A abordagem a partir de análises geoquímicas em amostras de sedimentos superficiais visa primeiramente caracterizar o material orgânico que abastece a decomposição e, consequentemente, a produção de nutrientes e a emissão de GEEs. Adicionalmente, por meio da variabilidade hidrológica a origem dos compostos orgânicos e os processos de transformação em elementos inorgânicos e gasosos podem ser relacionados às modificações no uso e na cobertura dos solos. Bacias de drenagem que agregam alto valor ecológico e possuem importância econômica, como os reservatórios utilizados para geração de energia, devem ser alvo de constante monitoramento (Barker et al. 2005). Da mesma forma, as condições ambientais do sistema aquático anteriores a qualquer impacto ou distúrbio, a variabilidade natural e até que ponto e níveis os impactos se manifestaram ao longo do tempo devem ser caracterizados (Smol 2008).

A dinâmica dos processos que envolvem a produção e a decomposição da matéria orgânica $(\mathrm{MO})$ varia nas escalas de tempo e espaço, representando importante etapa no ciclo do carbono. Em reservatórios, o material inundado inicia o processo de degradação. Posteriormente, organismos vivos pelágicos agem como recicladores da $\mathrm{MO}$ em suspensão e/ou dissolvida presente na coluna d'água. Estima-se que somente entre 1 e $10 \%$ da produção seja preservada nos sedimentos anualmente (Killops \& Killops 2005). No entanto, essa pequena parcela que alcança o sedimento é adicionada ao material inundado e em grande parte reciclada por organismos bentônicos detritívoros. Contudo, parte dessa MO pode resistir a essas condições, sendo incorporada aos sedimentos e formando, ao longo dos anos, ricos depósitos orgânicos. Nesse sentido, estudos que abrangem a qualidade dos sedimentos integram e registram a entrada, a produção e a transformação de elementos, tanto minerais como biogênicos, e ao considerar as variações espaciais e sazonais evitam uma visão reducionista do ambiente avaliado, normalmente incapaz de perceber a complexidade dos problemas ambientais (Battarbee et al. 2005).
Os sedimentos constituem verdadeiros arquivos de informação de natureza biogeoquímica, uma vez que suas camadas estão sequencialmente acumuladas e funcionam como pontos de convergência das diferentes atividades desenvolvidas na bacia hidrográfica, tanto no espaço como no tempo. Com isso, podem ser considerados como a memória da bacia de drenagem na qual estão inseridos (Mozeto 2004, Smol 2008, Yu et al. 2007). Tais informações históricas podem ser utilizadas para a reconstituição de mudanças tanto de ambientes aquáticos quanto dos ecossistemas terrestres adjacentes (Lotter \& Birks 2003, Birks \& Birks 2006).

Restos vegetais, ao serem degradados, incorporam-se aos solos deixando uma assinatura de sua composição. Identificar e quantificar a composição orgânica de sedimentos em reservatórios inundados fornece informações sobre a origem da composição vegetal, seu estado de degradação e os principais processos que ali ocorrem.

Diversas podem ser as fontes de MO nesses ambientes, tais como os produzidos in situ (autóctone): fitoplâncton, plantas aquáticas vasculares, leveduras, fungos, protozoários, zooplâncton, fauna e flora bentônicas e bactérias ou transportado de áreas distantes pelo escoamento superficial e pela calha dos rios (alóctone), podendo sofrer modificações químicas e biológicas nesses processos (Volkman 1986). Entre as fontes alóctones distingue-se, hoje, a origem natural daquela oriunda de atividades antrópicas (exemplo: efluentes industriais e domésticos, fertilizantes, agrotóxicos).

Vários métodos têm sido utilizados para determinar a origem da $\mathrm{MO}$ por meio dos marcadores geoquímicos. Entre as técnicas utilizadas estão: medidas elementares do carbono orgânico e do nitrogênio total, razão entre os isótopos estáveis do carbono $\left(\delta^{13} \mathrm{C}\right)$ e nitrogênio $\left(\delta^{15} \mathrm{~N}\right)$ e composições moleculares do carbono orgânico, como, por exemplo, os $n$-alcanos e esteróis (Meyers 1997). As fontes de plantas terrestres são enriquecidas em carbono e se diferem das fontes de microalgas que são enriquecidas em nitrogênio. Em conjunto com as razões dos isótopos do carbono $\left({ }^{13} \mathrm{C} /{ }^{12} \mathrm{C}\right.$ ) distinguem-se as árvores (empobrecidas em ${ }^{13} \mathrm{C}$ ) das gramíneas enriquecidas em ${ }^{13} \mathrm{C}$. Valores intermediários são relacionados a algas continentais. A razão entre os isótopos do nitrogênio $\left({ }^{15} \mathrm{~N} /{ }^{14} \mathrm{~N}\right)$ pode fornecer informações sobre processos de entrada e/ou ciclagem de nitrogênio (Martinelli et al. 2009).

Entre os lipídios, os $n$-alcanos e os esteróis revelam importantes informações sobre a fonte, o transporte e o destino da MO (Volkman et al.1992). Eles contêm um alto grau de informação estrutural (retida no esqueleto hidrocar- 
bônico após a sedimentação), podendo ser relacionado aos organismos precursores da biota. O colesterol ocorre principalmente no zooplâncton, enquanto nas plantas vasculares predominam o $\beta$-sitosterol, o estigmasterol e o campesterol (Carreira et al. 2002). Da mesma forma, os $n$-alcanos são componentes provenientes das ceras epicuticulares das folhas de plantas vascularizadas. Esses componentes são particularmente resistentes à degradação tornando-os convenientemente adequados para uso como biomarcadores de plantas superiores. Apresentam tipicamente cadeias carbônicas de comprimento entre $\mathrm{C}_{21}$ e $_{35}$ com forte predomínio de homólogos com número ímpar de carbono sobre os pares (os mais

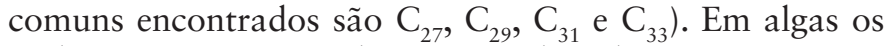
$n$-alcanos mostram predominância de cadeias com números de carbono entre $\mathrm{C}_{15}$ e $\mathrm{C}_{17}$ (Rieley et al. 1991, Schulz \& Zabel 2006). Para avaliar o predomínio entre plantas superiores e aquáticas a partir dos $n$-alcanos ou ainda a presença de fontes antropogênicas, trabalhos anteriores (Jaffé et al. 2001, Bouloubassi \& Saliot 1993) utilizaram alguns índices,

\section{MATERIAIS E MÉTODOS}

\section{1 Área de estudo}

O Reservatório do Funil (Figura 1) ocupa uma área de aproximadamente $40 \mathrm{~km}^{2}$ e volume total de 8,9 bilhões $\mathrm{m}^{3}$. Situa-se no município de Resende, na divisa entre os Estados do Rio de Janeiro e São Paulo, e foi construído para regularização da vazão e geração de energia elétrica. A capacidade nominal total de geração da Usina Hidrelétrica é de $216 \mathrm{MW}$ de potência (Vilhena et al.2003). Como a bacia do reservatório está, em sua quase totalidade, situada no Estado de São Paulo, as atividades desenvolvidas a montante e o tipo de como a razão entre o número de carbonos de cadeia curta sobre longa (CC/CL), a razão terrígeno e aquático (RTA) ou mesmo a quantificação da mistura complexa não resolvida (MCNR), indicativo de diagênese da MO.

O presente estudo analisou a composição orgânica dos sedimentos do Reservatório do Funil por meio das composições elementares, isotópicas e moleculares, com o objetivo de caracterizar as principais fontes e os processos que ocorrem desde sua entrada até a barragem. Construído no leito Rio Paraíba do Sul para geração de energia elétrica há aproximadamente cinco décadas, está localizado na região sudoeste do Estado do Rio de Janeiro. Atua como uma armadilha à poluição oriunda do Estado de São Paulo por meio da sedimentação; com isso, desenvolveu, nas últimas décadas, um acentuado processo de eutrofização. Devido a esse processo pode comprometer a qualidade da água do Rio Paraíba no trecho fluminense da bacia, que o emprega, entre outros usos, como principal manancial de abastecimento público de $80 \%$ da população do Estado do Rio de Janeiro.

ocupação e uso do solo no trecho paulista da Bacia do Rio Paraíba do Sul exercem extrema influência sobre a qualidade de água do reservatório (INEA 2009). O Reservatório do Funil foi construído em 1969, sendo, portanto, considerado um reservatório maduro, eutrofizado, com área de Mata Atlântica inundada e múltiplo uso da terra em seu entorno. Sua bacia de drenagem possui reduzida cobertura vegetal e seus solos estão sujeitos de modo significativo a processos erosivos (INEA 2009, Ferrão-Filho et al. 2009).

Figura 1

Mapa da área de estudo com a localização das estações de coleta de sedimento superficial, no Reservatório do Funil, Resende, RJ (círculos destacados: FL10, FL25, FL40, FL50).

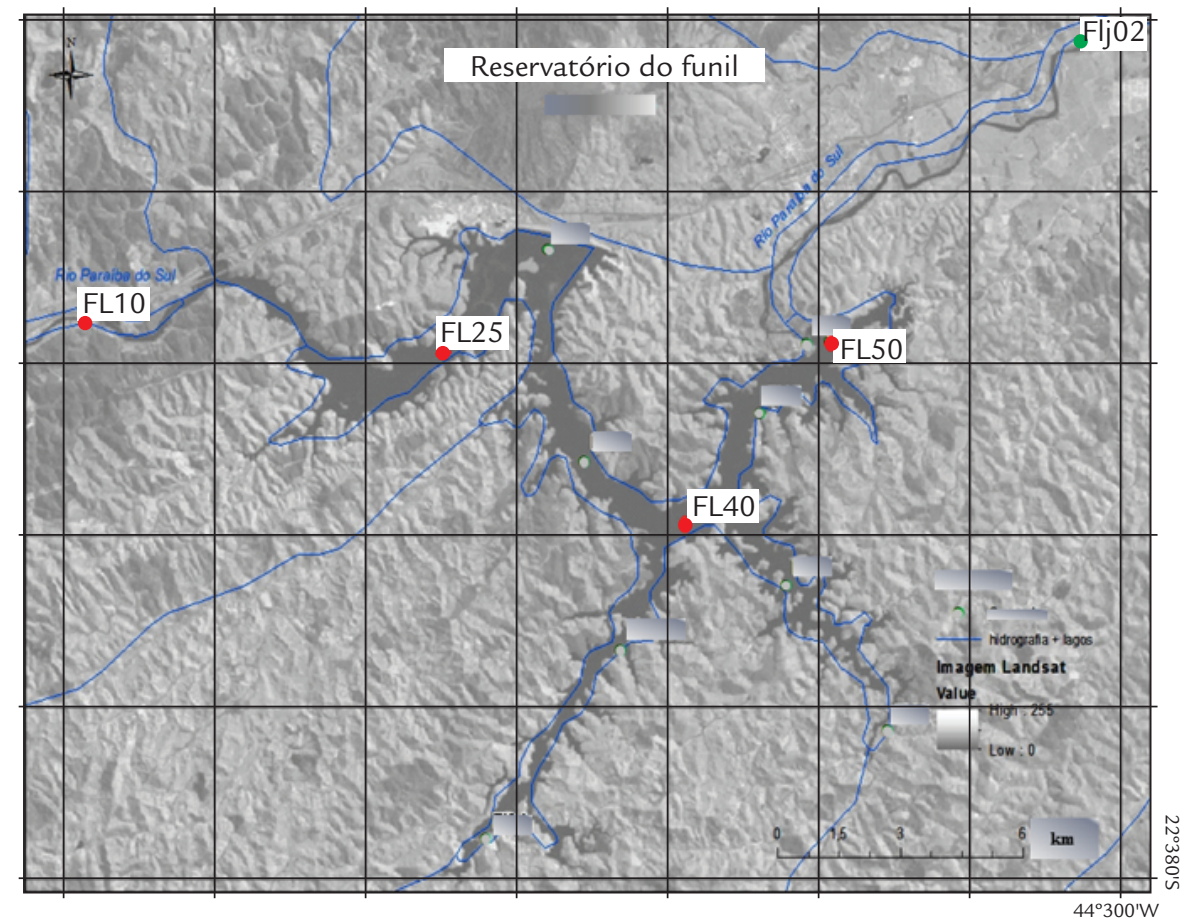




\subsection{Amostragem e métodos analíticos}

Sedimentos superficiais do Reservatório do Funil (RJ) foram coletados em junho de 2012 com o auxílio de um barco e de draga de Ekman. Foram 4 pontos de coleta distribuídos no reservatório da seguinte forma: 1 a montante, 2 centrais e 1 a jusante (Figura 1). No momento da coleta o sedimento foi seccionado de 0 a $5 \mathrm{~cm}$, estocado em frascos descontaminados e levado para laboratórios refrigerados. Em laboratório, as amostras foram secas em estufa a $30^{\circ} \mathrm{C}$, maceradas e utilizadas nas análises.

As amostras, depois de homogeneizadas, foram descarbonatadas com solução de $\mathrm{HCl} 0,1 \mathrm{~N}$ e pesadas em cápsulas de prata. Com o analisador Elementar ThermoFinnigan Delta Plus acoplado a um espectrômetro de massas foram realizadas as análises de carbono orgânico, nitrogênio total e razões isotópicas $\delta^{13} \mathrm{C}$ e $\delta^{15} \mathrm{~N}$. O método consiste na combustão do material a temperatura de $1020^{\circ} \mathrm{C}$ sob atmosfera de oxigênio puro, sendo que os gases gerados por condutividade térmica $\left(\mathrm{CO}_{2}\right.$ e $\left.\mathrm{N}_{2} \mathrm{O}\right)$ são carreados por meio de uma coluna cromatográfica até o espectrômetro de massas, para detecção. A quantificação é feita por comparação com padrões externos.

A metodologia para análises de esteróis e $n$-alcanos foi adaptada de Wakeham e Canuel (1988). Nessa metodologia, $3 \mathrm{~g}$ de sedimentos secos e homogeneizados são submetidos às etapas de extração total, fracionamento e leitura dos compostos em cromatografia gasosa. Os lipídios totais foram extraídos por intermédio da adição sequencial de $10 \mathrm{~mL}$ dos solventes: diclorometano (DCM), DCM:metanol (v:v) e metanol. A cada sequência de solventes adicionados, a amostra foi levada a banho-maria com ultrassom durante 15 minutos. Os sobrenadantes foram centrifugados e concentrados em evaporador rotativo a vácuo (Marconi - MA120 com condensador diagonal). Os extratos foram transferidos para vials de 1,8 ml e secos sob fluxo de nitrogênio. Em seguida foram fracionados em coluna de sílica para obtenção das frações relativas aos $n$-alcanos e esteróis. A amostra foi re-eluída com $1 \mathrm{~mL}$ de heptano e transferida para o topo de uma microcoluna cromatográfica feita em pipeta pasteur
( $23 \mathrm{~cm}$ de altura e $0,5 \mathrm{~cm}$ de diâmetro) preenchida com sílica gel (calcinada, ativada a $120^{\circ} \mathrm{C} / 24 \mathrm{~h}$ e desativada com $5 \%$ de água destilada) em heptano. Em seguida foram adicionados $2,5 \mathrm{~mL}$ de heptano para obtenção da fração $\mathrm{F}_{1}$, relativa aos $n$-alcanos; $2,5 \mathrm{~mL}$ de heptano:tolueno $(50 \%)$ para $\mathrm{F}_{2}$; $2,0 \mathrm{~mL}$ de heptano:acetato de etila $(10 \%)$ para $\mathrm{F}_{3} ; 3,5 \mathrm{~mL}$ de heptano:acetato de etila $(20 \%)$ para $\mathrm{F}_{4}$, relativa aos esteróis; $3,0 \mathrm{~mL}$ de acetato de etila para $\mathrm{F}_{5}$. Apenas as frações $\mathrm{F}^{1} \mathrm{e}$ $\mathrm{F}^{4}$ relativas aos $n$-alcanos e esteróis, respectivamente, foram recolhidas em vial de $1,8 \mathrm{~mL}$ e secas sob fluxo de nitrogênio. A derivatização foi feita com a adição de $25 \mu \mathrm{L}$ de BSTFA em $25 \mu \mathrm{L}$ de heptano para re-eluição da amostra, esta foi aquecida em forno a $50^{\circ} \mathrm{C}$ durante 10 minutos. A injeção de $2 \mu \mathrm{L}$ de amostra foi feita no modo com divisão a uma taxa de 1:25. Para identificação e quantificação de esteróis foi utilizado equipamento de cromatografia a gás (Agilent HP6890) com detector de ionização por chama e coluna capilar do tipo DB-5, com 30 metros de comprimento, 0,25 mm de diâmetro interno e $0,25 \mu \mathrm{m}$ de espessura de filme, composta por dimetilpolisiloxano (DB-5). A temperatura do injetor foi de $280^{\circ} \mathrm{C}$, e do detector, de $270^{\circ} \mathrm{C}$. Hidrogênio 5.0 FID foi utilizado com gás de arraste com fluxo constante de $1,4 \mathrm{~mL} / \mathrm{min}$. A programação da temperatura do forno foi de $100^{\circ} \mathrm{C}$ no início com rampa de $15^{\circ} \mathrm{C} / \mathrm{min}$ até $250^{\circ} \mathrm{C}$ e $1^{\circ} \mathrm{C} / \mathrm{min}$ até $300^{\circ} \mathrm{C}$ e isoterma de 3 minutos nesta temperatura.

Foram identificados os $n$-alcanos de $\mathrm{C}_{10}$ a $\mathrm{C}_{40}$. Os esteróis identificados neste trabalho foram: coprostanol

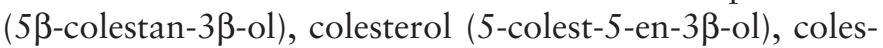
tanol ( $5 \alpha$-colestan- $3 \beta$-ol), colestanona ( $5 \alpha$-colestan- 3 -ona), ergosterol ((22E)-ergosta-5,7,22-trien-3 $\beta$-ol), campesterol

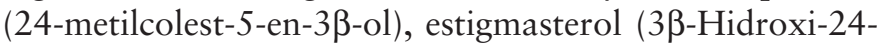
etil-5,22-colestadien), $\beta$-sitosterol (24-etilcolest-5-en-3 $\beta$-ol), $\beta$-sitostanol (24-etil-5 $\alpha$-colestan-3 $\beta$-ol) (Figura 2). Os compostos foram identificados comparando-se os padrões comerciais injetados previamente e as concentrações calculadas por intermédio de curva de calibração com 5 a-colestano.

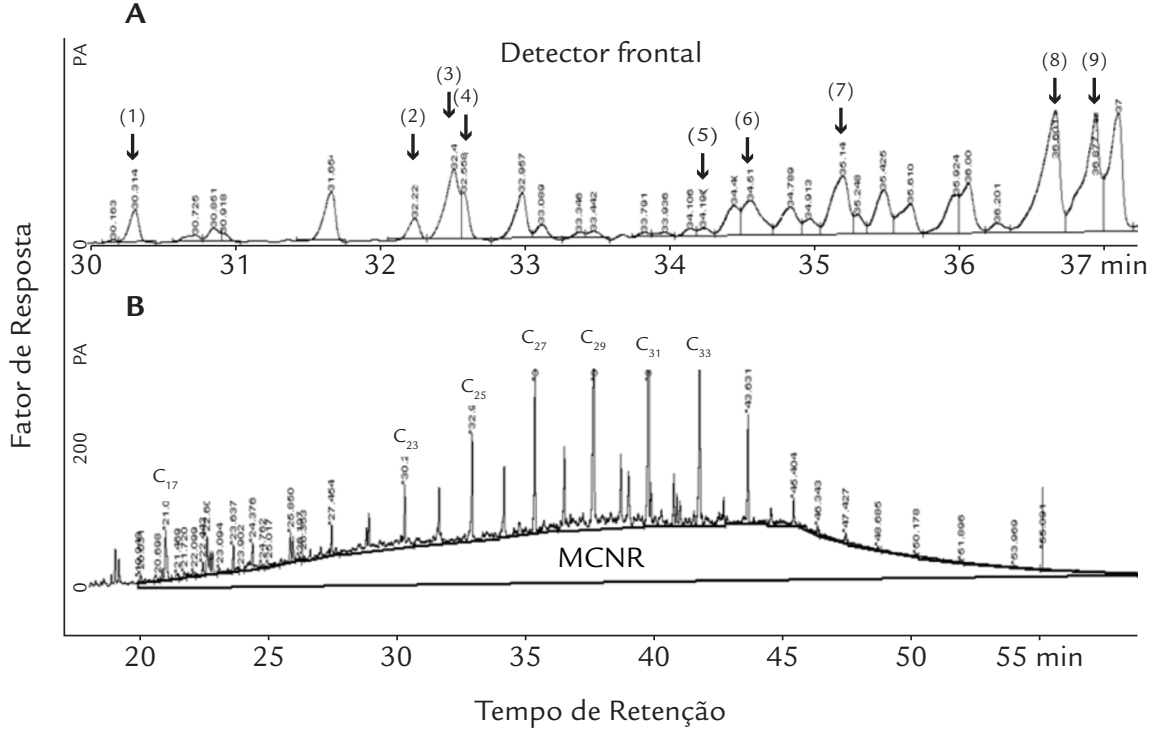

MCNR: mistura complexa não resolvida.
Figura 2

Cromatograma dos esteróis (A) e $n$-alcanos (B) identificados nos sedimentos do Reservatório do Funil (amostra FL10).

Compostos identificados em (A): (1) coprostanol, (2) colesterol, (3) colestanol, (4) colestanona, (5) ergosterol, (6) campesterol, (7) estigmasterol, (8) $\beta$-sitosterol, (9) $\beta$-sitostanol; e em (B): $n$-alcanos predominantes $C_{17}, C_{23}, C_{25}$, $\mathrm{C}_{27}, \mathrm{C}_{29}, \mathrm{C}_{31}, \mathrm{C}_{33}$. 


\section{RESULTADOS E DISCUSSÃO}

\subsection{Composição elementar e isotópica de carbono e nitrogênio}

As concentrações de carbono apresentaram gradiente decrescente, sendo maiores a montante e menores a jusante (Figura 3). Comportamento inverso foi observado nas concentrações de nitrogênio total. Dessa forma, a razão $\mathrm{C} / \mathrm{N}$ se mostrou maior a montante, com diminuição dos valores a jusante. Provavelmente, devido à leve queda nas concentrações de carbono orgânico e ao enriquecimento em nitrogênio, a razão $\mathrm{C} / \mathrm{N}$ variou entre 17,7 e 11,4 , tendo sido o maior valor observado no ponto FL50, a montante, e o valor mínimo no ponto FL10, a jusante (Figura 3). Os valores de $\delta^{13} \mathrm{C}$ variaram entre $-23,1$ e $-22,2$, enquanto valores de $\delta^{15} \mathrm{~N}$ variaram de 5,6 até 7,9 (Figuras 4A e 4B). Quando observados os valo- res isotópicos em conjunto, é possível visualizar facilmente um padrão de distribuição entre os pontos a montante e a jusante. Pontos a montante apresentam menores valores de $\delta^{15} \mathrm{C}$ e de $\delta^{15} \mathrm{~N}$, em comparação com as estações a jusante, demonstrando a predominância de material terrígeno nas estações localizadas próximo à entrada do reservatório e predomínio de atividade microbiana próximo à barragem. Micro-organismos que possuem capacidade fotossintética são encontrados normalmente dispersos e flutuando na coluna d'água associados a organismos heterotróficos. Dentre eles, os mais comuns são bactérias e algas (que após seu ciclo de vida são sedimentadas).
Figura 3

Composições elementares do carbono orgânico total (C Org em mg/g) e nitrogênio total ( $N$ total em $\mathrm{mg} / \mathrm{g}$ ) e suas razões atômicas $(\mathrm{C} / \mathrm{N})$ a (eixo secundário) nas estações de coleta de sedimentos FL10, FL25, FL40 e FL50 no Reservatório do Funil, Resende, RJ.
Figura 4

(A) Composições isotópicas do nitrogênio versus carbono.

(B) Razão atômica entre a composição elementar do carbono orgânico e nitrogênio total versus composição isotópica do carbono no

Reservatório do Funil, Resende, RJ.
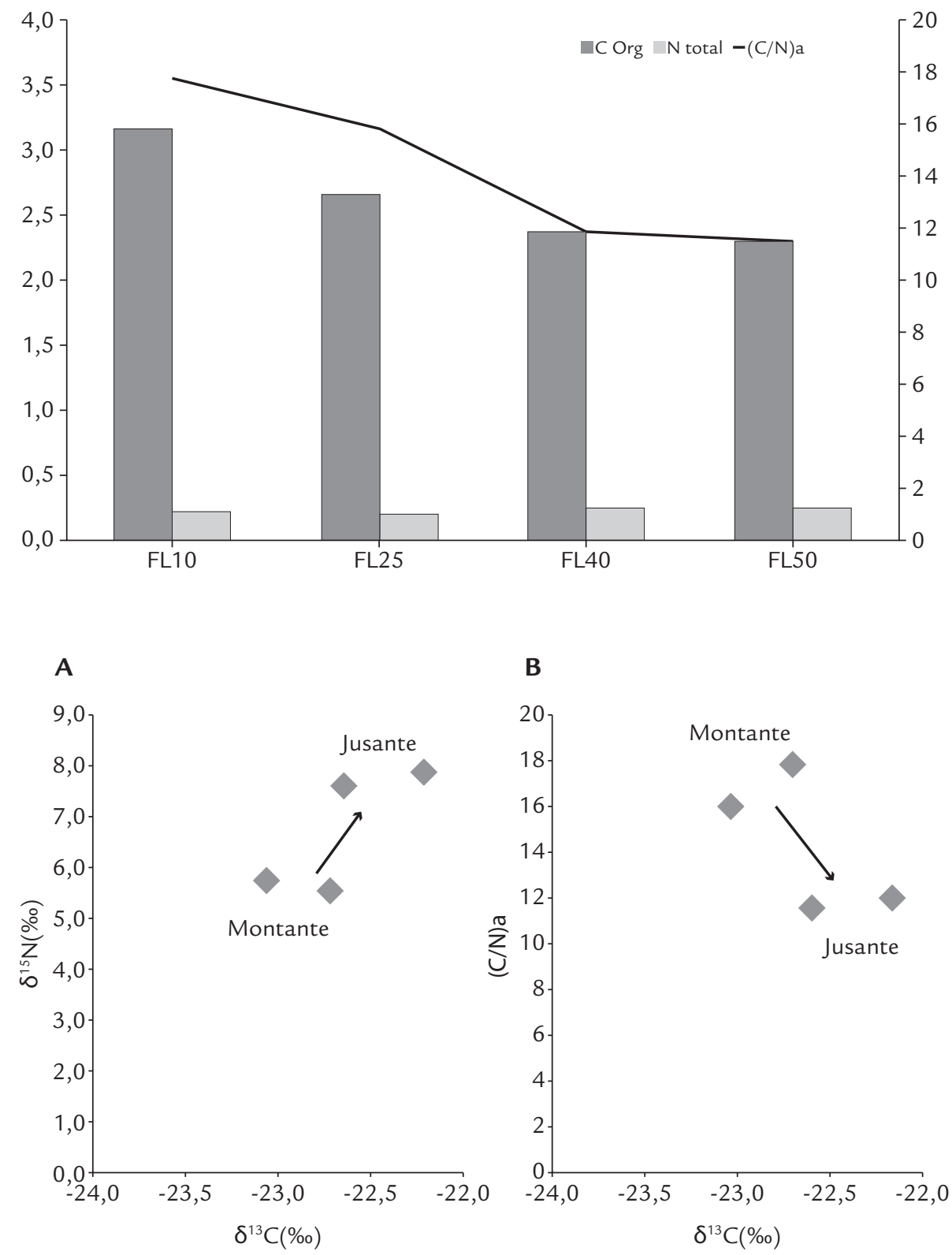
A Figura 5 relaciona os valores de $\delta^{15} \mathrm{~N}$ com a concentração de nitrogênio total. Nessa figura também é possível observar uma tendência de distribuição dos pontos em relação aos resultados. As amostras do centro da represa e próximo à barragem, a jusante, apresentam maiores

\subsection{Composição molecular de esteróis e n-alcanos}

Ao analisar os esteróis notam-se baixos valores de coprostanol e colestanona a montante, onde há um fluxo maior de água, quando comparados aos pontos no reservatório, onde há menor fluxo de água e, consequentemente, condições favoráveis para deposição e degradação da $\mathrm{MO}$ por ação bacteriana (Figura 6). Com isso, são observados no centro leve aumento de coprostanol e significável aumento dos valores de esteróis até a barragem, quando eles voltam a cair. Esse comportamento sugere entrada de coprostanol oriundo da bacia de drenagem a montante, posteriormente sua deposição e ao mesmo tempo intensificação dos processos de produção e degradação de $\mathrm{MO}$ na região central do reservatório.

Grimalt et al. (1990) estabeleceram uma razão uti-

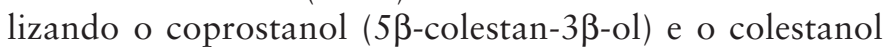
( $5 \alpha$-colestan-3 $\beta$-ol) para avaliar a influência de efluentes domésticos em ecossistemas aquáticos continentais. No entanto, para ambientes tropicais, Sabadini et al. (2008) sugerem que os valores da razão $[5 \beta /(5 \alpha+5 \beta]$ maior do concentrações de $\mathrm{N}$ e valores enriquecidos em ${ }^{15} \mathrm{~N}$. Esses resultados sugerem intensificação de processos internos (autóctones), enquanto as maiores concentrações de C no início do reservatório caracterizam transporte de $\mathrm{MO}$ terrestre de origem alóctone.

que 0,5 indicam sedimentos altamente contaminados por esgotos, enquanto valores menores do que 0,3 , ausência de contaminação. As concentrações de coprostanol confirmam a influência de efluentes domésticos em todo o reservatório, sendo mais acentuada na área FL25 e contaminada por esgotos domésticos (contaminação fecal) na área FL40 (Figuras 6 e 7). No entanto, no ponto de coleta FL50, a jusante, nota-se a diminuição desses valores. Esse resultado sugere um aumento da atividade bacteriana que age na degradação dessa MO, tornando essa área menos poluída no que se refere ao esgoto doméstico.

Ao comparar os valores de coprostanol e a razão $5 \beta /(5 \beta+5 \alpha)$ estanol (Tabela 1$)$ com outras regiões do Brasil e do Estado do Rio de Janeiro, os valores encontrados no reservatório do Funil ainda são intermediários ou inferiores. Isso se deve principalmente ao fato de que as regiões estudadas se localizam em regiões estuarinas, sujeitas a maior adensamento populacional, como, por exemplo, a Lagoa de Araruama e as Baías de Guanabara e Sepetiba.

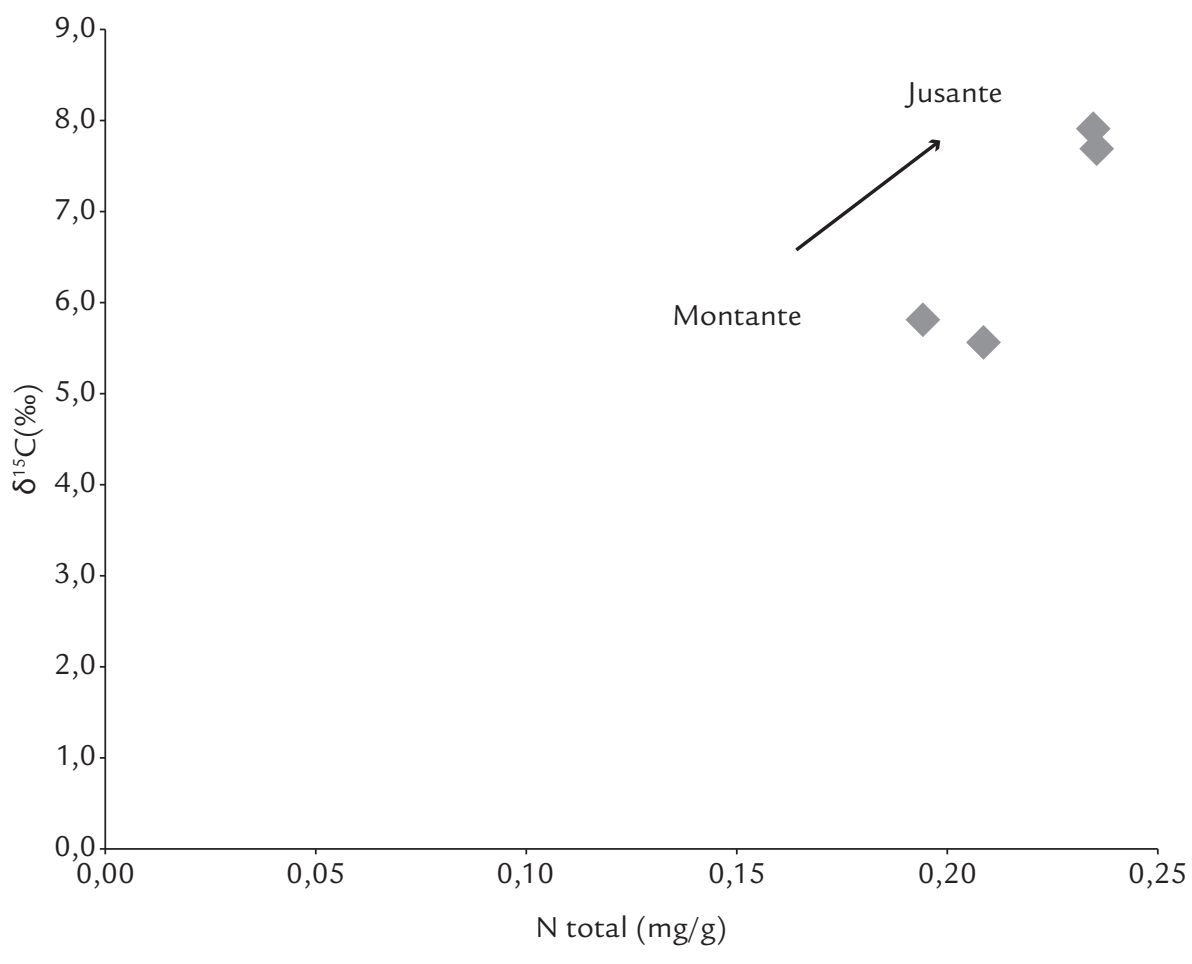

Figura 5

Composição isotópica do nitrogênio versus composição elementar do nitrogênio total no Reservatório do Funil, Resende, RJ. 
Os resultados da composição de hidrocarbonetos alifáticos ( $n$-alcanos) nos pontos de coleta do Reservatório do Funil mostram predomínio dos compostos de cadeia longa de número ímpar de carbonos $\left(\mathrm{C}_{29}, \mathrm{C}_{31}\right.$ e $\left.\mathrm{C}_{33}\right)$, indicando derivados de ceras cuticulares de plantas vasculares (terrestres) em todos os pontos de coleta, com maiores con- centrações nas estações de entrada (FL10 - rio) e no início do reservatório (FL25), com predomínio do $\mathrm{C}_{29}$ (Figura 8). Nas estações situadas no centro do reservatório (FL40) e próximas à barragem (FL50, a jusante), as concentrações de $n$-alcanos diminuem, com predominância de $\mathrm{C}_{31} \mathrm{e} \mathrm{C}_{33}$. A estação próxima à barragem apresenta relativo aumento do
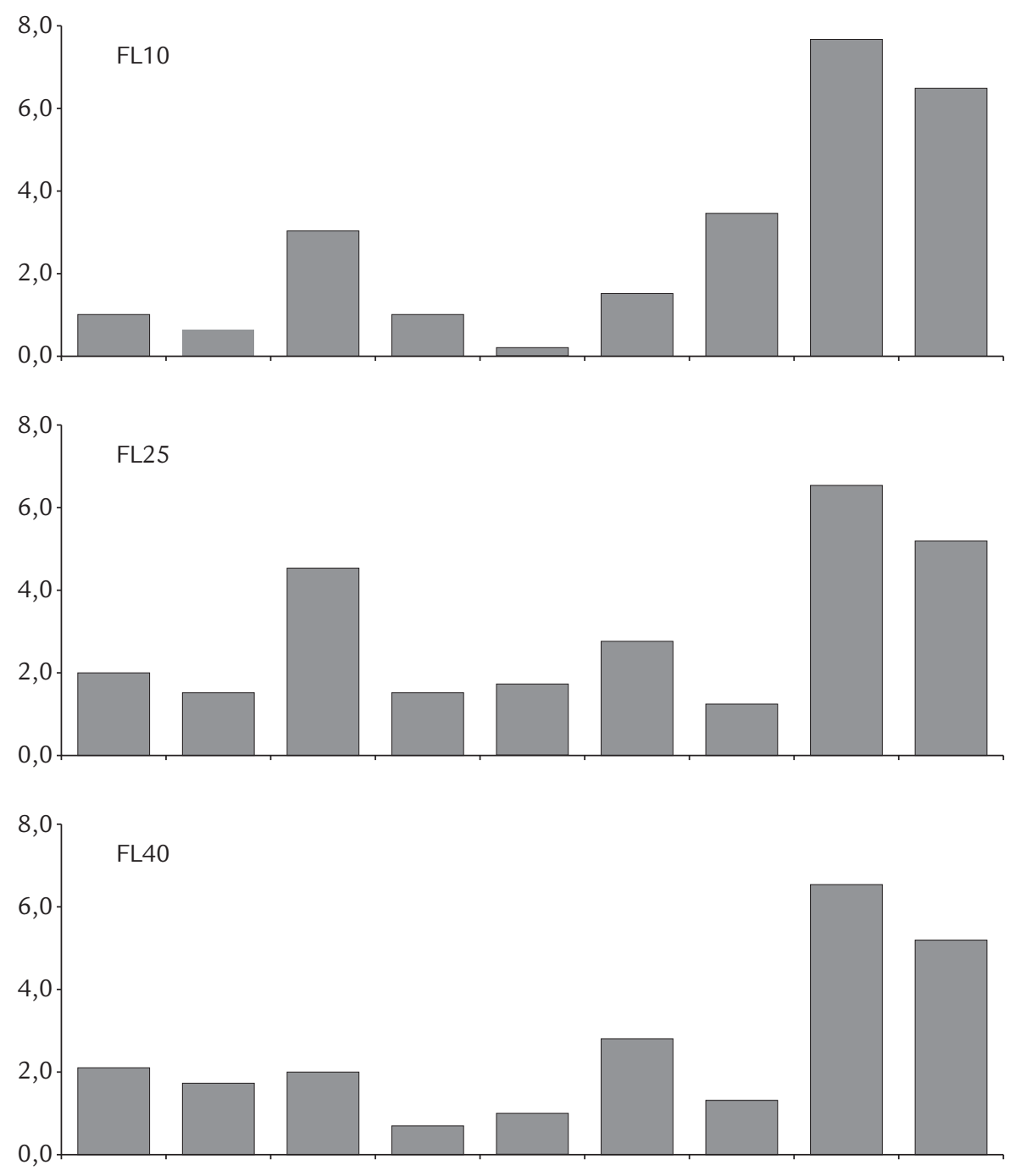

Figura 6

Esteróis $(e m \mu g / g)$ nas estações de coleta de sedimentos FL10, FL25, FL40 e FL50 no Reservatório do Funil, Resende, RJ.

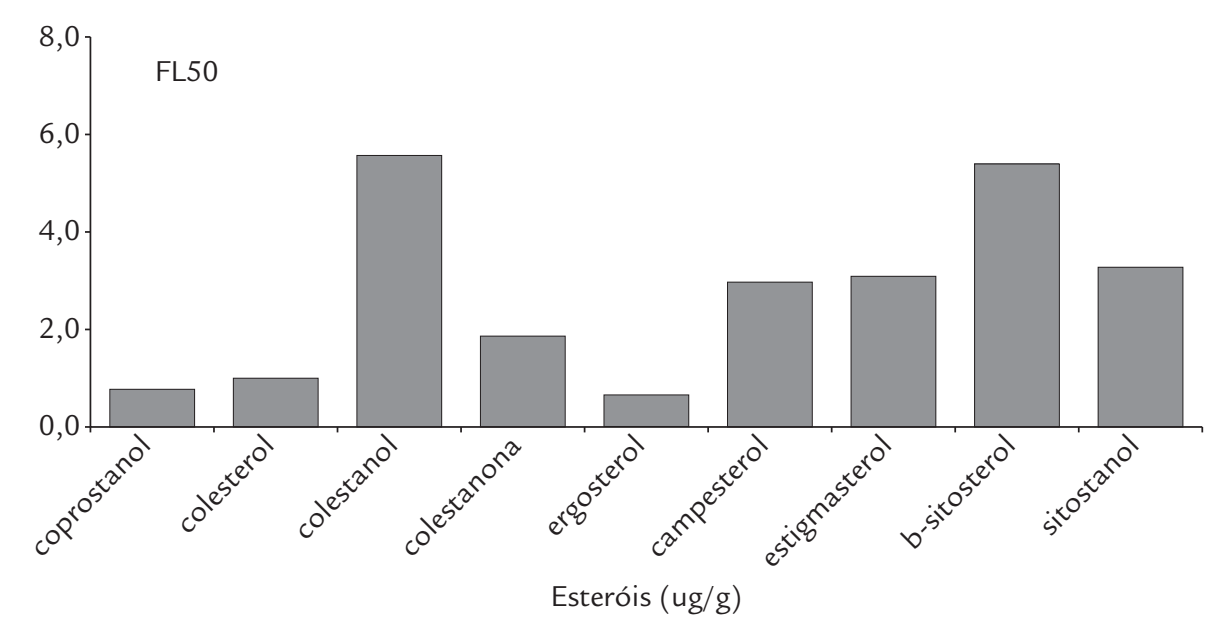




\begin{tabular}{|c|c|c|c|c|c|c|}
\hline Local & Coprostanol $(\mu g / g)$ & R Copro & n-alcanos $(\mu \mathrm{g} / \mathrm{g})$ & $\operatorname{MCNR}(\mu g / g)$ & RTA & Referência \\
\hline $\begin{array}{l}\text { Lagoa de } \\
\text { Araruama (RJ) }\end{array}$ & n.d. $-287,0$ & n.d. $-0,85$ & & & & Guerra 2008 \\
\hline $\begin{array}{l}\text { Lagoa dos } \\
\text { Patos (RS) } \\
\end{array}$ & n.d. $-0,92$ & & & & & Martins et al. 2007 \\
\hline $\begin{array}{l}\text { Lagoa Mundaú- } \\
\text { Manguaba (AL) }\end{array}$ & $0,15-5,65^{*}$ & n.d. $-0,39 *$ & $0,05-1,04 * *$ & & & $\begin{array}{l}{ }^{*} \text { Araujo et al. } 2011 \\
* * \text { Maioli et al. } 2012\end{array}$ \\
\hline $\begin{array}{l}\text { Baía de } \\
\text { Guanabara (RJ) }\end{array}$ & $0,33-105,0^{*}$ & $0,11-0,76^{*}$ & & $38,0-2 \cdot 127,0^{* *}$ & & $\begin{array}{c}{ }^{*} \text { Carreira et al. } 2004 \\
{ }^{*} \text { Santos et al. } 2008 \\
{ }^{*} \text { Costa \& Carreira } 2005 \\
\text { apud }{ }^{*} \text { *Carreira et al. } \\
2009\end{array}$ \\
\hline $\begin{array}{l}\text { Baía de } \\
\text { Santos (SP) }\end{array}$ & n.d. $-8,51^{*}$ & & & $39,7-2.015,0^{* *}$ & & $\begin{array}{c}{ }^{*} \text { Martins et al. } 2008 \\
\text { apud ** Carreira et al. } \\
2009\end{array}$ \\
\hline $\begin{array}{l}\text { Estuários do } \\
\text { Rio Paraíba do Sul, } \\
\text { Rio das Ostras e } \\
\text { Rio São João (RJ) }\end{array}$ & n.d. $-5,22$ & $0,10-0,70$ & $0,69-71,37$ & $1,39-251,6$ & $1,4-79,7$ & Savergnini 2013 \\
\hline $\begin{array}{l}\text { Canal do } \\
\text { Guandu e Baía } \\
\text { de Sepetiba (RJ) }\end{array}$ & n.d. $-3,97^{*}$ & $0,10-0,80 *$ & $0,10-53,50 *$ & $36,7-179,0^{* *}$ & $0,3-66,9 *$ & $\begin{array}{l}\text { *Thomazelli } 2010 \\
\text { **Figueiredo et al. } 2008\end{array}$ \\
\hline $\begin{array}{l}\text { Baía de } \\
\text { Sepetiba (RJ) }\end{array}$ & $0,01-0,42$ & $0,08-0,48$ & $0,26-2,65$ & n.d. $-17,4$ & $1,0-8,8$ & Carreira et al. 2009 \\
\hline $\begin{array}{l}\text { Estuário do } \\
\text { Rio Capibaribe (PE) }\end{array}$ & $0,52-7,30$ & & & & & Fernandes et al. 1999 \\
\hline $\begin{array}{l}\text { Reservatório } \\
\text { do Funil (RJ) }\end{array}$ & $0,83-2,05$ & $0,44-0,60$ & $16,72-27,21$ & $146,7-252,3$ & $3,2-9,2$ & Este estudo \\
\hline
\end{tabular}

MCRN: mistura complexa não resolvida; RTA: razão terrígeno aquático.

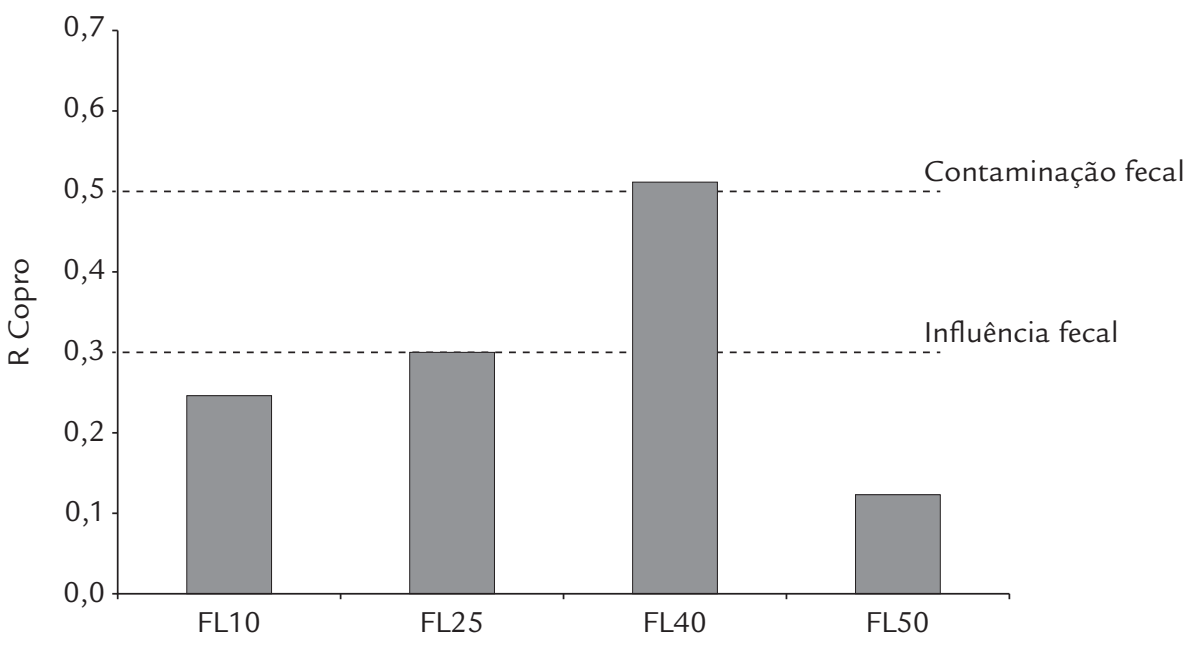

Tabela 1

Concentrações de coprostanol e valores da razão $\mathrm{R}$ Copro $[5 \beta /(5 \beta+5 \alpha)$ estanol], e concentrações de $n$-alcanos, mistura complexa não resolvida e razão terrígeno aquático $\left(\mathrm{RTA}=\left(\sum \mathrm{n}-\mathrm{C}_{27+29+31} / \sum \mathrm{n}-\mathrm{C}_{15+17+19}\right)\right.$ em diferentes regiões da Costa Brasileira.

Figura 7

Razão entre coprostanol e colestanol indicativa de contaminação dos sedimentos por esgotos domésticos nas estações de coleta de sedimentos FL10, FL25, FL40 e FL50 no Reservatório do Funil, Resende, RJ. Classificação segundo Grimalt et al. (1990), adaptado de Sabadini et al. (2008). 
composto $C_{17}$ no ambiente. Meyers et al. (1984) atribuíram a predominância desses $n$-alcanos em sedimentos do lago Michigan como fontes de micro-organismos (fitoplâncton), ao contrário de Souza (2011), que não identificou compostos $\mathrm{C}_{17}$ em seu trabalho realizado no Reservatório Vossoroca, no Estado do Paraná, Sul do Brasil, provavelmente devido a menor presença de micro-organismos e ao clima mais frio.
Volkman et al. (1992) definem a MCNR como uma mistura de hidrocarbonetos estruturalmente complexos, ramificados ou cíclicos, que não podem ser resolvidos pela coluna capilar do cromatógrafo devido a sua degradação incompleta. Conforme mostra a Figura 9, a atividade biogênica se apresenta predominantemente nos pontos a montante e menos influente nos pontos a jusante. Valores
Figura 8

Concentrações de $n$-alcanos nas estações de coleta de sedimentos

FL10, FL25, FL40 e FL50 no

Reservatório do Funil, Resende, RJ.

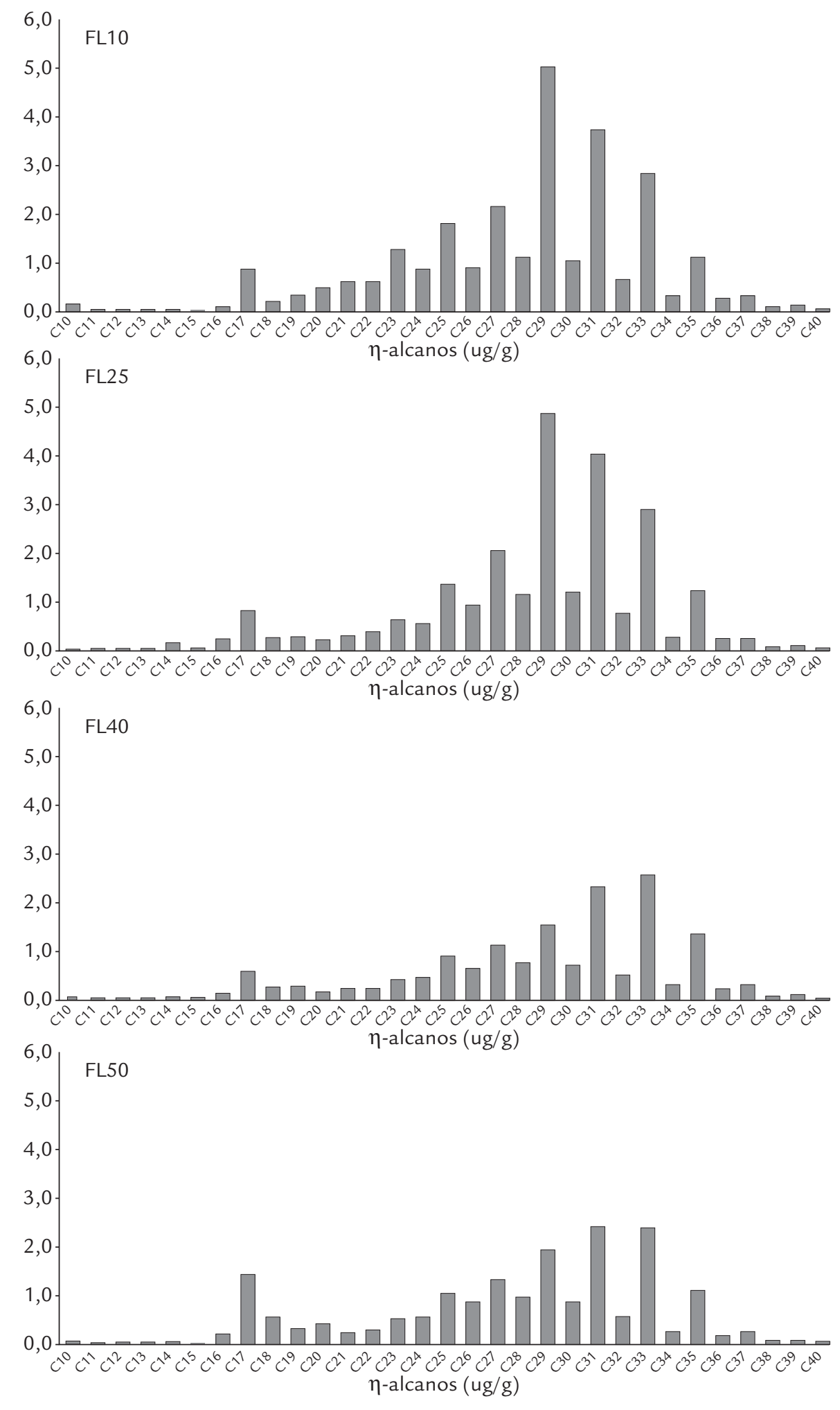



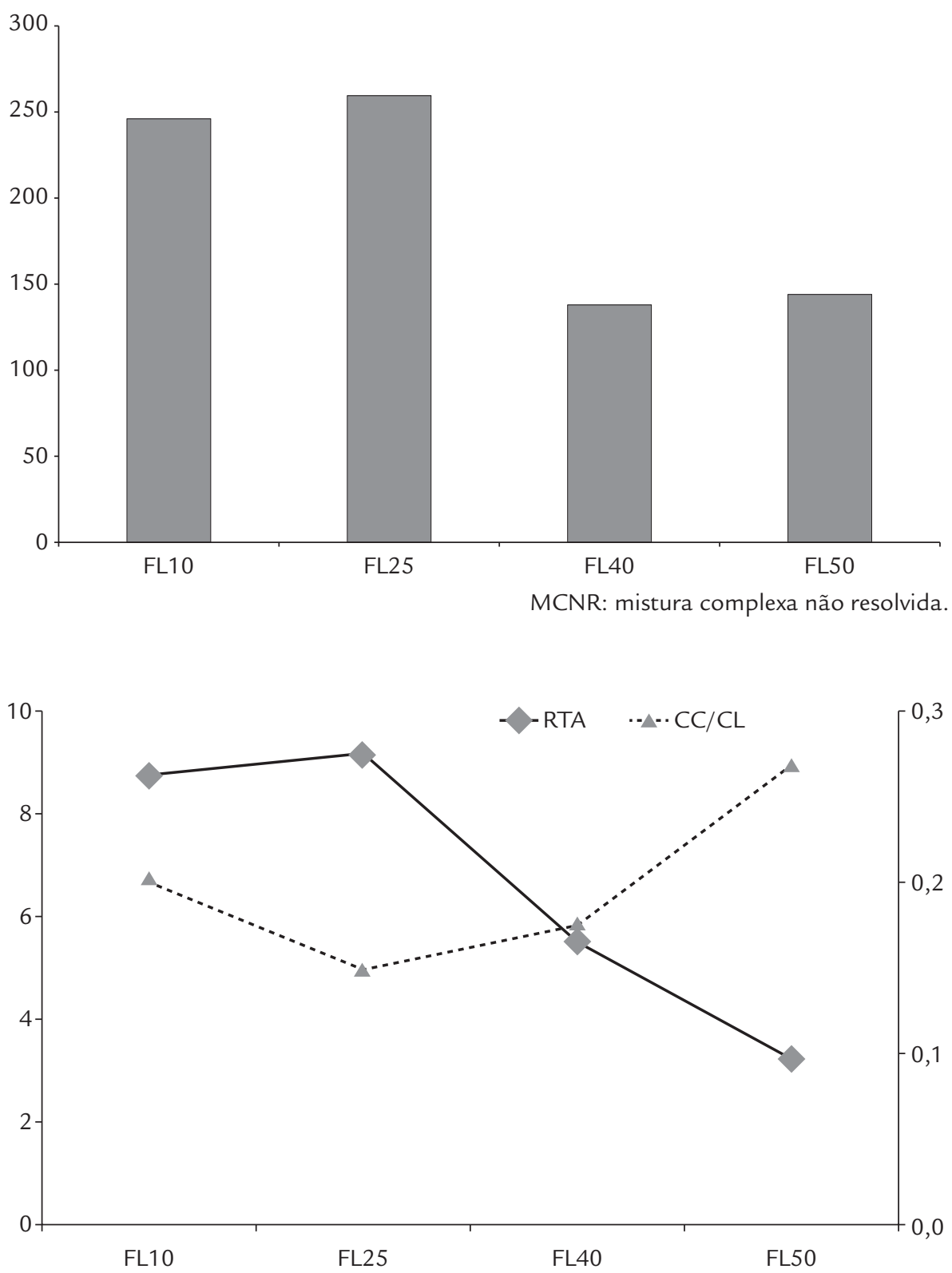

RTA: razão terrígeno e aquático; CC/CL: razão cadeias curtas/cadeias longas de $n$-alcanos nas estações de coleta de sedimentos.
Figura 9

Presença de mistura complexa não resolvida $(e m \mu g / g)$ nas estações de coleta de sedimentos FL10, FL25, FL40 E FL50 no Reservatório do Funil, Resende, RJ.
Figura 10

Razão terrígeno aquático e razão cadeias curtas/cadeias longas de $n$-alcanos nas estações de coleta de sedimentos FL10, FL25, FL40 e FL50 no Reservatório do Funil, Resende, RJ. similares foram encontrados no Canal do Guandu na Baía de Sepetiba (Thomazeli 2010, Figueiredo et al. 2008), e podem ser indicativo da presença de resíduos de petróleo já em processo de intemperização. No entanto, para regiões severamente contaminadas, como a Baía de Guanabara e a Baía de Santos, foram reportados valores de até duas ordens de grandeza superiores (apud Carreira et al. 2009) (Tabela 1).

Para melhor avaliar a contribuição de fontes de MO aquática e terrestre em estudos ambientais, podem ser utilizados alguns índices que indiquem origem, tais como a razão RTA (razão entre a MO de origem terrestre e a aquática).

$$
\mathrm{RTA}=\left(\mathrm{n}-\mathrm{C}_{27}+\mathrm{n}-\mathrm{C}_{29}+\mathrm{n}-\mathrm{C}_{31}\right) /\left(\mathrm{n}-\mathrm{C}_{15}+\mathrm{n}-\mathrm{C}_{17}+\mathrm{n}-\mathrm{C}_{19}\right)
$$

A RTA tem como base a distribuição de $n$-alcanos de maior e menor peso molecular, em que valores maiores do que 1 indicam o predomínio da MO de origem terrestre, e menores do que 1 , a predominância de compostos de menor peso molecular, derivados de fontes aquáticas, principalmente fitoplanctônica (Bourbonniere \& Meyers 1996).

No Reservatório do Funil ocorre o predomínio de MO de origem terrestre em quase toda a sua extensão, sendo observada queda na RTA quando próxima à barragem.

Um segundo índice foi aplicado para identificar a origem, a razão entre os $n$-alcanos de cadeia curta $\left(\mathrm{CC}=\mathrm{C}_{15}-\mathrm{C}_{23}\right)$ e os de cadeia longa $\left(\mathrm{CL}=\mathrm{C}_{23}-\mathrm{C}_{35}\right)$. Esse índice é determinado com base na distribuição de $n$-alcanos de baixo peso molecular, produzidos por micro-organismos, e $n$-alcanos de alto peso molecular, produzidos por plantas terrestres (Bourbonniere et al. 1997).

Os valores da razão CC/CL abaixo de 0,5 indicam maiores contribuições de plantas terrestres em todo o reservatório, com leve aumento da montante a jusante, indicativo de maior contribuição autóctone por micro-organismos (Bouloubassi \& Saliot 1993), mostrado na Figura 10. 


\section{CONCLUSÃO}

As análises sobre a composição da $\mathrm{MO}$ em sedimentos do Reservatório do Funil demonstram predomínio de fonte alóctone por meio de escoamento superficial de solos ricos em restos de plantas terrestres. Foi evidenciada também influência antropogênica devido à entrada de efluentes domésticos a montante. No centro do reservatório foi detectado o predomínio de processos autóctones devido à presença de compostos oriundos de micro-organismos. Os valores mais altos para carbono e baixos para nitrogênio nos pontos a montante (e a posterior inversão desse quadro) confirmam o início do Reservatório do Funil sob predominância de $\mathrm{MO}$ de origem alóctone e nos pontos próximos a jusante intensa atividade autóctone.

Os resultados de $n$-alcanos evidenciaram que o Reservatório do Funil possui uma grande área de floresta inundada devido à predominância de grupos fotossintéticos do tipo

\section{AGRADECIMENTOS}

Pauliana Almeida e Lais Barbosa agradecem à Fundação de Amparo à Pesquisa do Estado do Rio de Janeiro (FAPERJ), pelas bolsas de Iniciação Científica e Mestrado, respectivamente. Agradecemos ao Dr. Carlos Rezende, do Laboratório de Ciências Ambientas da Universidade Estadual do Norte Fluminense (LCA-UENF), pelas análises elementares e isotópicas. O suporte financeiro foi obtido por meio do Projeto
C3, e que o reservatório, em sua área inicial, sofre influência biogênica terrígena. Os valores mais pesados de $\delta^{13} \mathrm{C}$ e $\delta^{15} \mathrm{~N}$ indicaram predominância de micro-organismos fotossintéticos (fitoplâncton) a jusante do reservatório.

Foi comprovado por meio da análise de esteróis que o Reservatório do Funil recebe influentes fecais, tornando-se contaminado na região central, e, quando avaliada a condição ambiental nos pontos a jusante, nota-se que os processos de degradação autóctones conseguem conter esses compostos contaminantes, tornando esses ambientes menos poluídos. Por essas observações é possível afirmar que, apesar do processo de eutrofização, o reservatório age como um ambiente de decantação e depuração da MO de origem alóctone e antropogênica, possibilitando o seguimento do fluxo do Rio Paraíba do Sul, com águas contendo materiais mais refratários.
Eletronorte: "Limnologia e Metabolismo Planctônico controlando as taxas de transferência de Gases de Efeito Estufa". As análises orgânicas foram desenvolvidas no Laboratório de Geoquímica Orgânica da Universidade Federal Fluminense (UFF) com suporte do Instituto Nacional de Ciência e Tecnologia de Transferência de Materiais Continente-Oceano (CNPq-INCT-TMOcean, Processo no 573601/2008-9).

\section{REFERÊNCIAS}

Araujo M.P., Costa T.L.F., Carreira R.S. 2011. Esteróis como indicadores do acúmulo de esgotos domésticos em sedimentos de um sistema estuarinolagunar tropical (Mundaú-Manguaba, AL). Química Nova, 34(1):64-70.

Barker P.A., Pates J.M., Payne R.J., Healey R.M. 2005. Changing nutrient levels in Grasmere, English Lake District, during recent centuries. Freshwater Biology, 50(12):1971-1981.

Battarbee R.W., Anderson N.J., Jeppensen E., Leavitt P.R. 2005. Combining paleolimnological and limnological approaches in assessing lake ecosystem response to nutrient reduction. Freshwater Biology, 50:1772-1780.

Birks H., Birks H.J.B. 2006. Multi-proxy studies in paleolimnology. Vegetation History and Archaeobotany, 15:235-251.

Bourbonniere R.A., Telford S.L., Ziolkowski L.A., Lee J., Evans M.S., Meyers P.A. 1997. Biogeochemical Marker Profiles in Cores of Dated Sediments from Large North American Lakes. In: Eganhouse, R. P. (Ed.). Molecular Markers in Environmental Geochemistry. Washington, DC: American Chemical Society. p. 133-150.

Bourbonniere R.A., Meyers P.A. 1996. Sedimentary geolipid records of historical changes in the watersheds and productivities of Lakes Ontario and Erie. Limnology and Oceanography, 41(2):352-359.

Bouloubassi I., Saliot A. 1993. Investigation of anthropogenic and natural organic inputs in estuarine sediments using hydrocarbon markers (NAH, LAB, PAAH). Oceanologica Acta, 16(2):145-161.

Carreira R.S., Wagener A.L.R., Readman J.W., Fileman T.W., Macko S.A., Veiga A. 2002. Changes in the sedimentary organic carbon pool of a fertilized tropical estuary, Guanabara Bay, Brazil: an elemental, isotopic and molecular marker approach. Marine Chemistry, 79(3-4):207-227. 
Carreira R.S., Wagener A.L.R., Readman J.W. 2004. Sterols as markers of sewage contamination in a tropical urban estuary (Guanabara Bay, Brazil): space-time variations. Estuarine Coastal Shelf Science, 60(4):587-598.

Carreira R.S., Ribeiro P.V., Silva C.E.M. 2009. Hidrocarbonetos e esteróis como indicadores de fontes e destino de matéria orgânica em sedimentos da Baía de Sepetiba, Rio de Janeiro. Quimica Nova, 2(7):1805-1811.

Costa R.L., Carreira R.S. 2005. A comparison between faecal sterols and coliform counts in the investigation of sewage contamination in sediments. Brazilian Journnal of Oceanography, 53:157.

Fernandes M.B., Sicre M.A., Cardoso J. N., Macedo S. 1999. Sedimentary 4-desmethyl sterols and n-alkanols in an eutrophic urban estuary, Capibaribe River, Brazil. Journnal of Science Total Environmental, 23(1):1.

Ferrão-Filho A.S., Soares M.C., Rocha M.I.A., Magalhães V.F., Azevedo S.M.F.O. 2009. Florações de Cianobactérias tóxicas no Reservatório do Funil: dinâmica sazonal e consequências para o zooplankton. Oecologia Brasiliensis, 13(2):346-365.

Grimalt J.O., Fernandez P., Bayona J.M., Albaiges J. 1990. Assessment of faecal sterols and ketones as indicators of urban sewage inputs to coastal waters. Environmental Science \& Technology, 24(3):357-363.

Guerra L.V. 2008. Processos microbiológicos e composição da matéria orgânica relacionados à eutrofização de uma lagoa costeira hipersalina, L. Araruama, RJ. Niterói. Dissertação (Mestrado em Geoquímica Ambiental), Programa de PósGraduação em Geoquímica Ambiental, Universidade Federal Fluminense, 98 p.

INEA - Instituto Estadual do Meio Ambiente. 2009. Disponível em: www.inea. rj.gov.br/bacia_rio_paraiba_sul. Acessado em 22 fev. 2013.

Jaffé R., Mead R., Hernandez M.E., Peralba M.C., Di Guida O.A. 2001.Origin and transport of sedimentary organic matter in two subtropical estuaries: a comparative, biomarker-based study. Organic Geochemistry, 32(4):507-526.

Killops S.D., Killops V.J. 2005. An introduction to organic geochemistry. 2. ed. Oxford: Blackwell Publishing. 408 p.

Lotter A.F., Birks H.J.B. 2003. The Holocene paleolimnology of Sägistalsee and its environmental history - a synthesis. Journal of Paleolimnology, 30(3):333-342.

Maioli O.L.G., Oliveira C.R., Sasso M.A.D., Madureira L.A.S., Azevedo D.A., Aquino Neto F.R. 2012. Evaluation of the organic matter sources using the $\mathrm{d} 13 \mathrm{C}$ composition of individual n-alkanes in sediments from Brazilian estuarine systems by GC/C/IRMS. Estuarine, Coastal and Shelf Science, 114:140-147.

Martinelli L.A., Ometto J.P.H.B., Ferraz E.S., Victoria R.L., Camargo P.B., Moreira M.Z. 2009. Desvendando questões ambientais com isótopos estáveis. São Paulo: Oficina de Textos. 144 p.

Martins C.C., Fillmann G., Montone R.C. 2007. Natural and anthropogenic sterols inputs in surface sediments of Patos Lagoon, Brazil. Journnal of Brazilian Chemical Society, 18:106-115.

Martins C.C., Ferreira J.A., Taniguchi S., Mahiques M.M., Bícego M.C., Montone, R.C. 2008. Spatial distribution of sedimentary linear alkylbenzenes and faecal steroids of Santos Bay and adjoining continental shelf, SW Atlantic, Brazil: origin and fate of sewage contamination in the shallow coastal environment. Marine Pollution Bulletin, 56:1359.

Meyers P.A., Leenheer M.J., Eadie B.J., Maule S.J. 1984. Organic geochemistry of suspended and settling particulate matter in Lake Michigan. Geochimica et Cosmochimica Acta, 48(3):443-452.

Meyers P.A.1997. Organic geochemical proxies of paleoceanographic, paleolimnologic, and paleoclimatic processes. Organic Geochemistry, 27(5-6):213-250.

Mozeto A.A. 2004. Sedimentos e Particulados Lacustres: Amostragens e Análises Biogeoquímicas. In: Bicudo C.E.M. \& Bicudo D.C. (Org.). Amostragem em Limnologia. São Carlos: RiMa. 372 p.

Rieley G., Collier R.J., Jones D.M., Eglinton G. 1991. The biogeochemistry of Ellesmere Lake, U.K-I. Source correlation of leaf wax inputs to the sedimentary 
lipid record. Organic Geochemistry, 17(6):901-912.

Sabadini E.S., Carreira R.S., Knoppers B.A. 2008. Sedimentary sterols as indicators of environmental conditions in southeastern Guanabara Bay, Brazil. Brazilian Journal of Oceanography, 56(2):97-113.

Savergnini F. 2013. Composição e distribuição espacial da matéria orgânica sedimentar nos estuários do Rio Paraíba do Sul, Rio das Ostras e Rio São João, RJ. Niterói. Tese (Doutorado em Geoquímica Ambiental), Programa de PósGraduação em Geoquímica Ambiental, Universidade Federal Fluminense, 203 p.

Schulz H.D., Zabel M. 2006. Marine Geochemistry. 2. revised, updated and extended edition. Editora Springer, Berlim, 4. p. 125-168.

Souza D.B. 2011. Avaliação da composição geoquímica da matéria orgânica de sedimentos lacustres. Curso de Tecnologia em Química Ambiental do Departamento Acadêmico de Química e Biologia - DAQBI - UTFPR, Paraná Brasil.

Smol J.P. 2008. Pollution of lakes and rivers - A Paleoenvironmental Perspective. 2. ed. Blackwell Publishing, Oxford. 383 p.

Thomazelli F.F. 2010. Composição da matéria orgânica no gradiente estuarino da Baía de Sepetiba, RJ. Niterói. Tese (Doutorado em Geoquímica Ambiental), Programa de Pós-Graduação em Geoquímica Ambiental, Universidade Federal Fluminense, $145 \mathrm{p}$.

Vilhena R.M., Lacerroig H., Meseses P.R. 2003. Determinação do assoreamento de reservatório utilizando Técnicas de geoprocessamento, o caso do reservatório de Funil - RJ. In: Anais XI SBSR, Belo Horizonte, Brasil, INPE. p. 2649-2651.

Volkman J.K. 1986. A review of sterol markers for marine and terrigenous organic matter. Organic Geochemistry, 9(2):83-99.

Volkman J.K., Holdsworth G.D., Neil G.P., Bavor H.J. 1992. Identification of natural, anthropogenic and petroleum hydrocarbons in aquatic sediments. Science of The Total Environment, 112(2-3):203-219.

Wakeham S.G., Canuel E.A. 1988. Organic geochemistry of particulate matter in the eastern tropical north pacific ocean. Implications for particle dynamics. Journal of Marine Research, 46(1):183-213.

Yu G., Xue B., Lai G., Gui F., Liu X. 2007. A 200-year historical modeling of catchment nutrient changes in Taihu basin, China. Developments in Hydrobiologia, 194:79-87. 
